\section{Uma revisão bibliográfica sobre as estratégias de construção da autonomia nos serviços públicos brasileiros de atenção em saúde a usuários de drogas}

\author{
A literature review on strategies for building \\ autonomy in Brazilian healthcare services for \\ drug users
}

\section{Una revisión bibliográfica sobre las estrategias de construcción de la autonomía en los servicios públicos brasileños de atención en salud a consumidores de drogas}




\section{Introdução}

Os serviços e ações direcionados ao cuidado em saúde a pessoas que fazem uso abusivo de drogas se consolidaram nacionalmente no início dos anos 2000, a partir da Política para Atenção Integral a Usuários de Álcool e Outras Drogas (PAIUAD 2003) 1. Anteriormente, as políticas de Estado relacionadas às drogas por muito tempo estiveram confinadas aos estreitos e violentos espaços policiais, carcerários e manicomiais. A abordagem aos usuários, quando ocorria, era feita pela lógica do controle e da punição $2,3,4$.

A própria diferenciação entre o uso e o tráfico só se consolida no século XXI, há aproximadamente 15 anos, com a Resolução no 3/2005 do que, à época, era o Conselho Nacional Antidrogas (CONAD), possibilitando a abordagem específica sobre o uso abusivo sem contradições estritamente legais. O abuso de drogas se caracteriza por trazer danos físicos, psicológicos ou sociais, estando relacionado a uma diversidade de agravos à saúde, intensificando situações de vulnerabilidade e conflitos sociais 5 .

A inserção de um novo paradigma relativo às drogas se fundamenta nacionalmente na já citada PAIUAD 1. Esta efetivou um conjunto de arcabouços teóricos e suas práticas de cuidado que vinham sendo desenvolvidas em diferentes locais, dentre os quais estão a atenção psicossocial e a redução de danos, alinhados ao sistema público elaborado sob o campo da saúde coletiva. Conjunto este que passou a ser compreendido como paradigma psicossocial, ou da saúde coletiva, no campo das drogas 6,7. Entretanto a PAIUAD não fez que deixasse de ocorrer a disputa de espaço com as noções de controle e punição de cunho moral-biomédico ${ }^{8,9}$.

Esses arcabouços que compõem o paradigma psicossocial detêm em comum um importante pilar, que é a contraposição ao modelo biomédico-psiquiátrico e moral, modelo que, em conjunto a políticas econômico-liberais, conforma a guerra às drogas 10,11. O modelo biomédico e sua concepção de saúde foi muito criticado nas últimas décadas do século XX, por falhar no que diz respeito à explicação do processo saúde-adoecimento populacional, ao planejamento dos sistemas de saúde e à efetividade das ações de cuidado 12,13 .

Desta forma, esse novo direcionamento, baseado tanto em processos empíricos quanto no conceito ampliado de saúde, desenvolveu novas concepções no terreno coletivo do cuidado. Esse conceito de saúde coloca em evidência as condições de produção e reprodução da vida das populações, os vínculos estabelecidos sob estas condições e a singularidade dos sujeitos 14. Inaugura-se, assim, uma valorização da dimensão subjetiva e das potencialidades de usuários e profissionais, o que proporcionou novas perspectivas de reflexão e ação 15,16. Compreendeu-se que não só as ações institucionais incidem sobre a saúde dos sujeitos e grupos, mas também que as ações desses sujeitos podem e devem incidir sobre a saúde e a construção das práticas de cuidado. Conceito que unifica a importância da subjetividade e protagonismo dos sujeitos é o de construção de autonomia 17,18

A construção de autonomia, segundo Kinoshita 17, busca que os sujeitos sejam reconhecidos enquanto detentores de valor social, não sendo menos responsáveis devido a seu sofrimento e diagnóstico, sendo necessário respeitar sua vontade nas práticas de cuidado. Além disso, destina-se a possibilitar sua participação na construção de um novo lugar social aos excluídos pela estigmatização. Amarante 19 enfatiza que a principal maneira de avaliar os serviços provenientes da reforma psiquiátrica, como os atuais serviços no campo das drogas, deve ser o grau de autonomia construído entre usuários, profissionais e sociedade, e que deve sempre ocorrer um estranhamento das ações e locais de cuidado, para evitar que a transformação da lógica de cuidado não se torne meramente uma reorganização tecnocrática e institucional.

Logo, a construção pelo cuidado de sujeitos autônomos é objetivo dos processos terapêuticos nos serviços de atenção em saúde a pessoas que fazem uso abusivo de drogas. E os arcabouços que compõem a nova política de cuidado trouxeram inúmeras ações e concepções que desenvolvem a noção de construção de autonomia 20,21.

Não há, entretanto, estudo que congregue essas diferentes ações práticas executadas em diferentes realidades. Ainda, o embate com a política de guerra às drogas tem sido intenso, o que pode fazer que o desenvolvimento do fundamento de construção de autonomia, ocorrido nos anos de concretização do paradigma psicossocial, possa ser perdido. Exemplo desse embate é o esvaziamento da redução de danos na política nacional sobre drogas, por meio do Decreto no 9.761/2019, que assevera a abstinência total, além de grandes investimentos públicos que vêm ocorrendo em comunidades terapêuticas, 
superando o financiamento de toda a Rede de Atenção Psicossocial (RAPS) 22. Modificações na legislação da atenção básica também vêm acarretando restrição de financiamento, possível diminuição no número de agentes comunitários de saúde (ACS) e despriorização do caráter territorial das equipes do Núcleo Ampliado de Saúde da Família (NASF) 23,24.

Dessa forma, este estudo busca descrever as estratégias de construção de autonomia identificadas nos serviços de saúde, possibilitando produzir um panorama acerca da rede de atenção psicossocial e verificar se as ações estão de acordo com objetivos e diretrizes da política de saúde mental e drogas. Além de propiciar, mediante o desmonte dessa política, apontar quais são suas transformações necessárias, inclusive para embasar a avaliação das modificações em curso.

O objetivo deste artigo, portanto, é descrever as estratégias de construção de autonomia identificadas nos serviços públicos brasileiros de atenção à saúde a pessoas que fazem uso abusivo de crack, álcool e outras drogas, por meio de uma revisão integrativa.

\section{Método}

Este estudo se caracteriza enquanto pesquisa bibliográfica de cunho qualitativo. A pesquisa seguiu as etapas metodológicas para o desenvolvimento de revisões integrativas de literatura 25.

A revisão integrativa corresponde a um método que proporciona agregar conhecimentos de diferentes pesquisas acerca de uma mesma temática, inclusive pesquisas de disciplinas distintas e métodos também distintos 26,27. Logo, possibilita a síntese de resultados, desde que os dados sejam organizados e analisados de maneira rigorosa, explicitando-se seus fundamentos e sua metodologia 27 . A revisão integrativa permite abordar diferentes objetivos, como definição de conceitos, revisão de teorias ou análise metodológica dos estudos 25,26 .

É importante ressaltar que a revisão integrativa propicia a compreensão do cuidado em saúde, uma vez que este se caracteriza enquanto trabalho complexo, requerendo colaboração e integração de diferentes áreas do conhecimento; destaca-se não somente pelo desenvolvimento da base de políticas e procedimentos, mas também acerca do pensamento crítico que exige o cuidado em saúde 28 . Ercole et al. 25 asseveram que a variedade na composição da amostra em conjunção com a multiplicidade de finalidades proporciona como resultado um quadro "de conceitos complexos, de teorias ou problemas relativos ao cuidado na saúde" 25 (p. 9).

\section{Seleção e organização}

No período de agosto e setembro de 2019, foram realizadas as buscas nas bases de dados PsycInfo, PubMed, Biblioteca Virtual em Saúde (BVS) e Web of Science.

As buscas foram realizadas seguindo um protocolo adequado a cada base, sobretudo conforme descritores ou palavras-chave encontradas em seus thesaurus, mas também em dicionários linguísticos e idiomáticos. Assim, cada uma delas foi acessada com os descritores e combinações a seguir, com termos no singular e plural.

Termos do protocolo de busca em português: (Serviço de Saúde Mental, Serviço de Higiene Mental, Centro de Atenção Psicossocial, Centro de Tratamento de Abuso de Substâncias, Centro de Tratamento de Dependentes de Drogas Ilícitas, Centro de Tratamento de Toxicômanos, Centro de Tratamento de Abuso de Drogas, Centro de Reabilitação de Drogados, Caps, Caps-AD, Consultório na rua, Unidade Básica de Saúde, Atenção Primária, Saúde da Família) AND (usuário de drogas, dependente químico, drogadito, farmacodependente, viciado em drogas, drogas ilícitas, drogas de abuso, drogas recreativas, drogas, crack, cocaina, álcool) AND (autonomia, autonomia pessoal, empoderamento, cidadania, direitos do paciente, direitos civis).

Termos do protocolo de busca em inglês: (Mental Health Services, Mental Hygiene Services, Substance Abuse Treatment Centers, Drug Rehabilitation Centers, Drug Abuse Treatment Centers, Drug Treatment Centers, Psychosocial Care Centers, Caps, Caps-AD, primary health care, family health, street clinic, street office, street outreach office) AND (drug user, drug abuser, addict, drug-dependent, doper, druggie, stoner, junkie, drugs, crack, cocaine, alcohol, street drugs, drug abuse) AND (personal autonomy, free will, self-determination, empowerment, freedom of choice, civil rights, client rights, interpersonal control, autonomy, patient's rights). 
Após a pesquisa nas bases de dados com os protocolos de busca e a exclusão dos estudos duplicados no programa EndNote Web (https://endnote.com/), foram aplicados os critérios de exclusão e inclusão, elaborados a partir do objetivo da pesquisa. Os critérios de exclusão foram: (1) estudos nos quais a população ou o objeto de estudo não eram brasileiros; (2) a temática era distinta ao cuidado a pessoas que fazem uso abusivo de drogas; (3) o local de estudo não correspondia aos serviços públicos ou os dados acerca do local/serviço eram insuficientes; (4) os estudos abordavam aspectos que não permitiam a análise da construção de autonomia; (5) os dados do estudo não eram primários. Foram selecionados estudos que: (1) abordassem o conceito de autonomia e (2) detivessem dados primários. Verificados esses critérios, restaram 19 artigos. Após a leitura dos artigos, três outros foram adicionados, a partir das referências bibliográficas. O fluxo de seleção e exclusão está sintetizado na Figura 1.

Para os resultados aqui apresentados, seguimos os passos para análise de dados qualitativos desenvolvidos por Minayo 29, que incluem: ordenação dos dados, classificação e análise final. A etapa de

\section{Figura 1}

Etapas de seleção dos estudos.

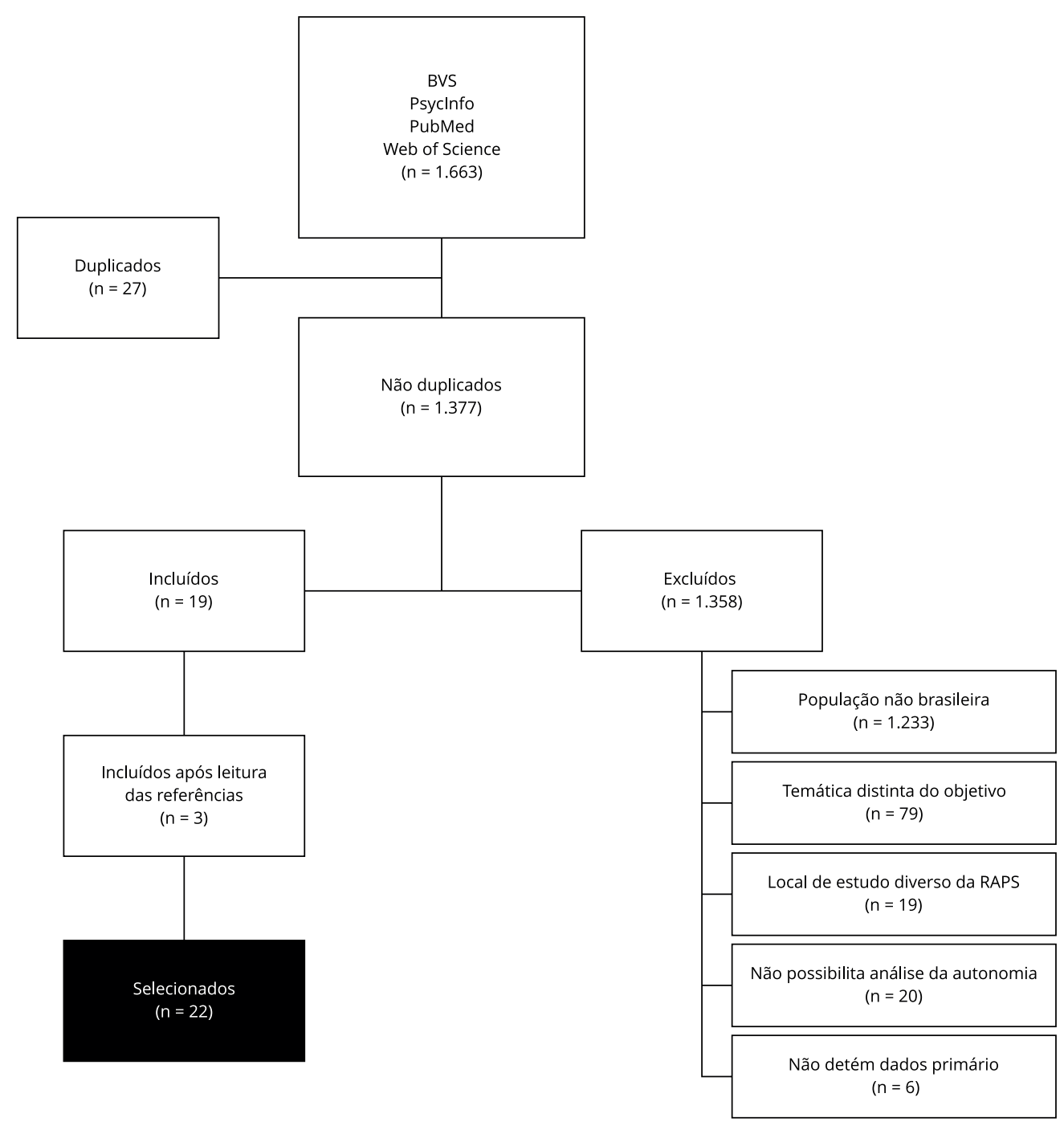

BVS: Biblioteca Virtual em Saúde; RAPS: Rede de Atenção Psicossocial. 
ordenação corresponde ao mapeamento dos dados encontrados. A etapa de classificação diz respeito ao levantamento de informações relevantes acerca do conteúdo dos dados, com base em questionamentos que se sustentam na fundamentação teórica, podendo realizar-se a elaboração de categorias-síntese. Na etapa de análise final, busca-se realizar articulações entre os dados e os referenciais teóricos, articulações que devem ser direcionadas para os objetivos da pesquisa.

\section{Percurso de análise}

Para sistematizar e descrever as ações e barreiras na estratégia de construção de autonomia dos serviços abordados nos estudos selecionados, foram realizadas as etapas descritas a seguir.

A primeira etapa corresponde ao desenvolvimento de um instrumento de sistematização, que se refere ao Quadro 1. Este apresenta um conjunto de 16 ações relativas ao processo de construção de autonomia e cinco principais dificuldades.

Essas 16 ações e cinco dificuldades foram selecionadas e organizadas a partir de três referências: as diretrizes da RAPS 30, as orientações que constam em material técnico da Secretaria Nacional de Políticas sobre Drogas (SENAD) 4, e os princípios da atenção psicossocial, conforme Yasui 31, tendo como fruto o Quadro 1.

As ações descritas no Quadro 1 foram divididas em três dimensões, correspondentes às três primeiras colunas. Estas provêm da síntese conceitual acerca da construção de autonomia, feita principalmente com base em Kinoshita 17, Merhy 18 e Onocko-Campos \& Campos 32. São elas: (1) dimensão da singularidade: resgate de autonomia no processo terapêutico; (2) dimensão dos vínculos: construção corresponsável de autonomia; e (3) dimensão social e política: construção de autonomia em amplitude coletiva.

A segunda etapa corresponde à verificação de quais ações do Quadro 1 são desenvolvidas nos serviços estudados e quais barreiras na estratégia de construção de autonomia foram encontradas nos estudos selecionados. Essa verificação foi elaborada a partir da leitura exaustiva dos 22 estudos.

\section{Quadro 1}

Ações e iniciativas relativas às dimensões de autonomia.

\begin{tabular}{|c|c|c|c|}
\hline $\begin{array}{l}\text { DIMENSÃO DA SINGULARIDADE: } \\
\text { RESGATE DE AUTONOMIA NO } \\
\text { PROCESSO TERAPÊUTICO }\end{array}$ & $\begin{array}{c}\text { DIMENSÃO DOS VÍNCULOS: } \\
\text { CONSTRUÇÃO CORRESPONSÁVEL } \\
\text { DE AUTONOMIA }\end{array}$ & $\begin{array}{c}\text { DIMENSÃO SOCIAL E POLÍTICA: } \\
\text { CONSTRUÇÃO DE AUTONOMIA } \\
\text { EM AMPLITUDE COLETIVA }\end{array}$ & $\begin{array}{c}\text { DIFICULDADES PARA A } \\
\text { CONSTRUÇÃO DE AUTONOMIA }\end{array}$ \\
\hline $\begin{array}{l}\text { (1) Atendimento em liberdade; } \\
\text { (2) Acolhimento e profissional de } \\
\text { referência; } \\
\text { (3) Desenvolvimento de PTS; } \\
\text { (4) Serviço territorial; } \\
\text { (5) Não obrigatoriedade de } \\
\text { abstinência; } \\
\text { (6) Realização de grupos e oficinas. }\end{array}$ & $\begin{array}{l}\text { (7) Corresponsabilização no PTS; } \\
\text { (8) Atividades territoriais (centro } \\
\text { de convivência, praças, teatro etc.); } \\
\text { (9) Cuidado em rede (UBS/CAPS, } \\
\text { CRAS, escola...), ARCTs, SRTs; } \\
\text { (10) Participação da família no } \\
\text { serviço; } \\
\text { (11) Estratégias/Oficinas de } \\
\text { redução de danos. }\end{array}$ & $\begin{array}{l}\text { (12) Organização/Gestão coletiva } \\
\text { do serviço/assembleias; } \\
\text { (13) Iniciativas de geração de } \\
\text { emprego e renda; } \\
\text { (14) Participação do conselho e } \\
\text { conferência local de saúde; } \\
\text { (15) Grupo de teatro/rádio/banda/ } \\
\text { coral do serviço; } \\
\text { (16) Desenvolvimento de } \\
\text { associação de usuários, familiares, } \\
\text { profissionais e ex-usuários. }\end{array}$ & $\begin{array}{l}\text { (A) Exigência de abstinência; } \\
\text { (B) Estigmatização/Patologização } \\
\text { pelos profissionais; } \\
\text { (C) Dificuldades na relação com } \\
\text { dispositivos da rede intersetorial/ } \\
\text { falta de rede; } \\
\text { (D) Falta de profissionais ou } \\
\text { capacitação profissional; } \\
\text { (E) Falta de estrutura. }\end{array}$ \\
\hline
\end{tabular}

ARCT: atenção residencial de caráter transitório; CAPS: Centro de Atenção Psicossocial; CRAS: Centro de Referência da Assistência Social; PTS: projeto terapêutico singular; SRT: serviços residenciais terapêuticos; UBS: unidades básicas de saúde.

Fonte: elaboração própria. 


\section{Resultados e discussão}

Apresentamos inicialmente os dados de identificação e publicação dos 22 estudos selecionados no Quadro 2. Nele constam a formação do primeiro autor em nível de graduação, o ano de publicação, a revista na qual o estudo foi publicado, o título, a categorização e o local do serviço de saúde, e o objetivo do estudo.

\section{Quadro 2}

Dados de caracterização dos estudos selecionados.

\begin{tabular}{|c|c|c|c|c|c|c|}
\hline ESTUDO & $\begin{array}{c}\text { 10 AUTOR } \\
\text { (FORMAÇÃO) }\end{array}$ & ANO & $\begin{array}{l}\text { REVISTA (BASE DE } \\
\text { DADOS) }\end{array}$ & TÍTULO & LOCAL & OBJETIVO \\
\hline 163 & $\begin{array}{c}\text { Ribeiro JP } \\
\text { (Enfermagem) }\end{array}$ & 2019 & $\begin{array}{l}\text { Investigación y } \\
\text { Educación en } \\
\text { Enfermería (BVS) }\end{array}$ & $\begin{array}{c}\text { Strategies of Care for } \\
\text { Adolescent Users of Crack } \\
\text { Undergoing Treatment }\end{array}$ & $\begin{array}{l}\text { CAPS AD e CAPSi } \\
\text { (interior do Rio } \\
\text { Grande do Sul) }\end{array}$ & $\begin{array}{l}\text { Analisar as estratégias de } \\
\text { cuidado ao adolescente } \\
\text { usuário de crack em } \\
\text { tratamento }\end{array}$ \\
\hline 264 & $\begin{array}{c}\text { Lago RR } \\
\text { (Enfermagem) }\end{array}$ & 2018 & $\begin{array}{l}\text { International Journal } \\
\text { of Mental Health \& } \\
\text { Addiction (Psyclnfo) }\end{array}$ & $\begin{array}{l}\text { An Exploration of the } \\
\text { Relational Autonomy of People } \\
\text { with Substance Use Disorders: } \\
\text { Constraints and Limitations }\end{array}$ & $\begin{array}{l}\text { CAPS AD (Região } \\
\text { Norte do Brasil) }\end{array}$ & $\begin{array}{l}\text { Analisar como pessoas que } \\
\text { fazem uso abusivo de drogas } \\
\text { exercem sua autonomia nos } \\
\text { serviços de saúde mental }\end{array}$ \\
\hline 365 & $\begin{array}{l}\text { Vasconcelos MP } \\
\text { (Psicologia) }\end{array}$ & 2018 & Gerais (BVS) & $\begin{array}{c}\text { o Cuidado aos Usuários de } \\
\text { Drogas: Entre Normatização e } \\
\text { Negação da Autonomia }\end{array}$ & $\begin{array}{c}\text { CAPS AD e CT (Minas } \\
\text { Gerais) }\end{array}$ & $\begin{array}{l}\text { Compreender as concepções } \\
\text { de profissionais que atuam } \\
\text { na RAPS acerca do cuidado } \\
\text { de pessoas com problemas } \\
\text { devido ao uso de drogas }\end{array}$ \\
\hline 447 & $\begin{array}{c}\text { Peiter P } \\
\text { (Arquitetura/ } \\
\text { Geografia) }\end{array}$ & 2018 & $\begin{array}{l}\text { Social Science and } \\
\text { Medicine (Psyclnfo) }\end{array}$ & $\begin{array}{c}\text { Homeless Crack Cocaine Users: } \\
\text { Territories and Territorialities } \\
\text { in the Constitution of Social } \\
\text { Support Networks For Health }\end{array}$ & $\begin{array}{l}\text { Consultório na Rua } \\
\text { (cidade do Rio de } \\
\text { Janeiro) }\end{array}$ & $\begin{array}{l}\text { Analisar como usuários de } \\
\text { crack no Rio de Janeiro se } \\
\text { relacionam com território e } \\
\text { constroem redes de apoio } \\
\text { com desafios e necessidades } \\
\text { de saúde cotidianos }\end{array}$ \\
\hline 566 & $\begin{array}{c}\text { Subrinho } \\
\text { Queiroz L } \\
\text { (Enfermagem) }\end{array}$ & 2018 & $\begin{array}{c}\text { Saúde e Sociedade } \\
\text { (BVS) }\end{array}$ & $\begin{array}{c}\text { Cuidado ao Consumidor } \\
\text { de Drogas: Percepção de } \\
\text { Enfermeiros da Estratégia de } \\
\text { Saúde da Família }\end{array}$ & $\begin{array}{l}\text { UBS (Vitória/Espírito } \\
\text { Santo) }\end{array}$ & $\begin{array}{l}\text { Compreender como } \\
\text { enfermeiros da Estratégia } \\
\text { Saúde da Família percebem o } \\
\text { cuidado aos consumidores de } \\
\text { drogas nas unidades de saúde }\end{array}$ \\
\hline 667 & $\begin{array}{l}\text { Galhardi C } \\
\text { (Terapia } \\
\text { Ocupacional) }\end{array}$ & 2018 & $\begin{array}{c}\text { Cadernos de Saúde } \\
\text { Pública (BVS) }\end{array}$ & $\begin{array}{c}\text { O Cotidiano de Adolescentes } \\
\text { em um Centro de Atenção } \\
\text { Psicossocial de Álcool e Outras } \\
\text { Drogas: Realidades e Desafios }\end{array}$ & $\begin{array}{l}\text { CAPS AD (interior de } \\
\text { São Paulo) }\end{array}$ & $\begin{array}{l}\text { Compreender o cotidiano } \\
\text { de adolescentes em relação } \\
\text { às drogas no CAPS AD e } \\
\text { demais contextos pelos quais } \\
\text { transitam, sob a ótica dos } \\
\text { adolescentes }\end{array}$ \\
\hline 768 & $\begin{array}{l}\text { Santos JM } \\
\text { (Terapia } \\
\text { Ocupacional) }\end{array}$ & 2018 & $\begin{array}{l}\text { Revista Gaúcha de } \\
\text { Enfermagem (BVS) }\end{array}$ & $\begin{array}{c}\text { Responsabilização e } \\
\text { Participação: Como Superar } \\
\text { o Caráter Tutelar no Centro } \\
\text { de Atenção Psicossocial Álcool } \\
\text { Drogas? }\end{array}$ & $\begin{array}{c}\text { CAPS AD (Ouro } \\
\text { Preto/Minas Gerais) }\end{array}$ & $\begin{array}{l}\text { Analisar o grau de } \\
\text { responsabilização e } \\
\text { participação do usuário em } \\
\text { tratamento no CAPS AD sob } \\
\text { a perspectiva da política de } \\
\text { redução de danos }\end{array}$ \\
\hline
\end{tabular}

(continua) 


\begin{tabular}{|c|c|c|c|c|c|c|}
\hline ESTUDO & $\begin{array}{c}\text { 10 AUTOR } \\
\text { (FORMAÇÃO) }\end{array}$ & ANO & $\begin{array}{l}\text { REVISTA (BASE DE } \\
\text { DADOS) }\end{array}$ & TítULO & LOCAL & OBJETIVO \\
\hline 859 & $\begin{array}{c}\text { Lacerda CB } \\
\text { (Serviço Social) }\end{array}$ & 2017 & $\begin{array}{l}\text { Interface - } \\
\text { Comunicação, Saúde, } \\
\text { Educação (Web of } \\
\text { Science) }\end{array}$ & $\begin{array}{c}\text { Significados e Sentidos } \\
\text { Atribuídos ao Centro de } \\
\text { Atenção Psicossocial Álcool e } \\
\text { Outras Drogas (CAPS AD) por } \\
\text { seus Usuários: Um Estudo de } \\
\text { Caso }\end{array}$ & $\begin{array}{c}\text { CAPS AD II } \\
\text { (Campinas/São } \\
\text { Paulo) }\end{array}$ & $\begin{array}{l}\text { Apresentar significados } \\
\text { e sentidos atribuídos por } \\
\text { usuários a um CAPS AD }\end{array}$ \\
\hline 969 & $\begin{array}{l}\text { Paula ML } \\
\text { (Psicologia) }\end{array}$ & 2017 & $\begin{array}{l}\text { Ciência \& Saúde } \\
\text { Coletiva } \\
\text { (PubMed) }\end{array}$ & $\begin{array}{c}\text { Experiências de Adolescentes } \\
\text { em Uso de Cracke } \\
\text { seus Familiares com a } \\
\text { Atenção Psicossocial e } \\
\text { Institucionalização }\end{array}$ & $\begin{array}{c}\text { CAPS AD II, CAPSi II e } \\
\text { abrigo de referência } \\
\text { (Fortaleza/Ceará) }\end{array}$ & $\begin{array}{l}\text { Compreender as implicações } \\
\text { da atenção psicossocial e } \\
\text { da institucionalização no } \\
\text { atendimento às necessidades } \\
\text { de adolescentes em situação } \\
\text { de uso de crack e de seus } \\
\text { familiares }\end{array}$ \\
\hline 1070 & $\begin{array}{c}\text { Silveira M } \\
\text { (Enfermagem) }\end{array}$ & 2017 & $\begin{array}{l}\text { Ciência, Cuidado e } \\
\text { Saúde (BVS) }\end{array}$ & $\begin{array}{c}\text { Autonomia e Reinserção Social: } \\
\text { Percepção de Familiares e } \\
\text { Profissionais que Trabalham } \\
\text { com Redução de Danos }\end{array}$ & $\begin{array}{l}2 \text { CAPS AD (extremo } \\
\text { sul do Brasil) }\end{array}$ & $\begin{array}{l}\text { Identificar a percepção de } \\
\text { familiares de dependentes } \\
\text { de álcool e outras drogas e } \\
\text { profissionais da saúde sobre } \\
\text { concepções de autonomia } \\
\text { e reinserção social que } \\
\text { embasam a abordagem de } \\
\text { redução de danos }\end{array}$ \\
\hline 1171 & $\begin{array}{c}\text { Lago RR } \\
\text { (Enfermagem) }\end{array}$ & 2017 & $\begin{array}{c}\text { Substance Abuse } \\
\text { Treatment, } \\
\text { Prevention, and Policy } \\
\text { (PubMed) }\end{array}$ & $\begin{array}{c}\text { Harm Reduction and Tensions } \\
\text { in Trust and Distrust in a } \\
\text { Mental Health Service: } A \\
\text { Qualitative Approach }\end{array}$ & $\begin{array}{l}\text { CAPS AD (Região } \\
\text { Norte do Brasil) }\end{array}$ & $\begin{array}{l}\text { Explorar as relações entre } \\
\text { usuários, profissionais, } \\
\text { familiares e sociedade sob } \\
\text { ações e o olhar a respeito da } \\
\text { redução de danos }\end{array}$ \\
\hline 1272 & $\begin{array}{c}\text { Nasi C } \\
\text { (Enfermagem) }\end{array}$ & 2015 & $\begin{array}{l}\text { Revista de Pesquisa, } \\
\text { Cuidado é } \\
\text { Fundamental Online } \\
\text { (Web of Science) }\end{array}$ & $\begin{array}{l}\text { O Trabalho da Equipe } \\
\text { Orientado pelas Motivações } \\
\text { dos Usuários no Capsad: } \\
\text { Estudo Fenomenológico }\end{array}$ & $\begin{array}{l}\text { CAPS AD III (Porto } \\
\text { Alegre/Rio Grande } \\
\text { do Sul) }\end{array}$ & $\begin{array}{c}\text { Compreender o trabalho } \\
\text { da equipe de um CAPS AD } \\
\text { orientado pelas motivações } \\
\text { dos usuários }\end{array}$ \\
\hline 1358 & $\begin{array}{l}\text { Wandekoken K } \\
\text { (Enfermagem) }\end{array}$ & 2015 & $\begin{array}{c}\text { Revista Subjetividades } \\
\text { (BVS) }\end{array}$ & $\begin{array}{c}\text { Biopolítica na Assistência aos } \\
\text { Usuários de Álcool e Outras } \\
\text { Drogas }\end{array}$ & CAPS AD & $\begin{array}{c}\text { Analisar as estratégias } \\
\text { biopolíticas que operam na } \\
\text { assistência aos usuários de } \\
\text { álcool e outras drogas }\end{array}$ \\
\hline 1449 & $\begin{array}{c}\text { Cardoso MP } \\
\text { (Enfermagem) }\end{array}$ & 2014 & Aletheia (BVS) & $\begin{array}{l}\text { A Percepção dos Usuários } \\
\text { sobre a Abordagem de Álcool } \\
\text { e Outras Drogas na Atenção } \\
\text { Primária à Saúde }\end{array}$ & $\begin{array}{l}\text { UBS (Caxias do Sul/ } \\
\text { Rio Grande do Sul) }\end{array}$ & $\begin{array}{c}\text { Conhecer a percepção } \\
\text { dos usuários sobre as } \\
\text { ações desenvolvidas pelos } \\
\text { profissionais da atenção } \\
\text { primária à saúde, visando } \\
\text { identificar ações relevantes } \\
\text { na abordagem do abuso de } \\
\text { drogas }\end{array}$ \\
\hline 1545 & $\begin{array}{c}\text { Vasconcelos SC } \\
\text { (Enfermagem) }\end{array}$ & 2013 & $\begin{array}{c}\text { Revista Enfermagem } \\
\text { UERJ (BVS) }\end{array}$ & $\begin{array}{l}\text { Demandas de Autocuidado em } \\
\text { Grupo Terapêutico: Educação } \\
\text { em Saúde com Usuários de } \\
\text { Substâncias Psicoativas }\end{array}$ & $\begin{array}{l}\text { CAPS AD (Recife/ } \\
\text { Pernambuco) }\end{array}$ & $\begin{array}{l}\text { Identificação das demandas } \\
\text { terapêuticas de autocuidado } \\
\text { entre usuários de substâncias } \\
\text { psicoativas por meio do grupo } \\
\text { educação em saúde }\end{array}$ \\
\hline
\end{tabular}

(continua) 


\begin{tabular}{|c|c|c|c|c|c|c|}
\hline ESTUDO & $\begin{array}{c}\text { 10 AUTOR } \\
\text { (FORMAÇÃO) }\end{array}$ & ANO & $\begin{array}{l}\text { REVISTA (BASE DE } \\
\text { DADOS) }\end{array}$ & TítULO & LOCAL & OBJETIVO \\
\hline 1673 & $\begin{array}{c}\text { Zanatta AB } \\
\text { (Enfermagem) }\end{array}$ & 2012 & $\begin{array}{l}\text { Revista Baiana de } \\
\text { Saúde Pública }\end{array}$ & $\begin{array}{c}\text { O Centro de Atenção } \\
\text { Psicossocial Álcool e Drogas } \\
\text { sob a Percepção do Usuário }\end{array}$ & $\begin{array}{c}\text { CAPS AD (oeste de } \\
\text { Santa Catarina) }\end{array}$ & $\begin{array}{l}\text { Estudar as experiências dos } \\
\text { usuários de um CAPS AD } \\
\text { e avaliar a importância do } \\
\text { serviço na sua recuperação }\end{array}$ \\
\hline 1774 & $\begin{array}{c}\text { Moura FG } \\
\text { (Terapia } \\
\text { Ocupacional) }\end{array}$ & 2011 & $\begin{array}{l}\text { SMAD, Revista } \\
\text { Eletrônica Saúde } \\
\text { Mental Álcool e } \\
\text { Drogas (BVS) }\end{array}$ & $\begin{array}{c}\text { O Cuidado aos Usuários de um } \\
\text { Centro de Atenção Psicossocial } \\
\text { Álcool e Drogas: Uma Visão do } \\
\text { Sujeito Coletivo }\end{array}$ & $\begin{array}{c}\text { CAPS AD (Salvador/ } \\
\text { Bahia) }\end{array}$ & $\begin{array}{l}\text { Analisar a percepção de } \\
\text { usuários acerca do cuidado } \\
\text { ofertado no CAPS AD }\end{array}$ \\
\hline 1875 & $\begin{array}{l}\text { Giffoni FA } \\
\text { (Medicina) }\end{array}$ & 2011 & $\begin{array}{l}\text { Revista Latino- } \\
\text { Americana de } \\
\text { Enfermagem (BVS) }\end{array}$ & $\begin{array}{c}\text { Terapia Comunitária como } \\
\text { Recurso de Abordagem do } \\
\text { Problema do Abuso do Álcool, } \\
\text { na Atenção Primária }\end{array}$ & $\begin{array}{c}4 \text { Varas de atenção } \\
\text { primária (Fortaleza/ } \\
\text { Ceará) }\end{array}$ & $\begin{array}{l}\text { Identificar potencialidades } \\
\text { da terapia comunitária como } \\
\text { recurso de abordagem do } \\
\text { abuso do álcool na atenção } \\
\text { primária, sob a perspectiva de } \\
\text { um usuário }\end{array}$ \\
\hline 1976 & $\begin{array}{c}\text { Oliveira E } \\
\text { (Enfermagem) }\end{array}$ & 2010 & $\begin{array}{c}\text { Revista de Terapia } \\
\text { Ocupacional da } \\
\text { Universidade de São } \\
\text { Paulo }\end{array}$ & $\begin{array}{c}\text { Práticas Assistenciais no } \\
\text { Centro de Atenção Psicossocial } \\
\text { de Álcool, Tabaco e Outras } \\
\text { Drogas }\end{array}$ & $\begin{array}{l}\text { CAPS AD (cidade de } \\
\text { São Paulo) }\end{array}$ & $\begin{array}{l}\text { Identificar e analisar as } \\
\text { representações que os } \\
\text { profissionais de um CAPS AD } \\
\text { constroem acerca das práticas } \\
\text { assistenciais desenvolvidas }\end{array}$ \\
\hline 2077 & $\begin{array}{l}\text { Pinho PH } \\
\text { (Psicologia) }\end{array}$ & 2009 & $\begin{array}{l}\text { Revista da Escola de } \\
\text { Enfermagem da USP }\end{array}$ & $\begin{array}{l}\text { Reabilitação Psicossocial dos } \\
\text { Usuários de Álcool e Outras } \\
\text { Drogas: A Concepção de } \\
\text { Profissionais de Saúde }\end{array}$ & $\begin{array}{l}\text { CAPS AD (Estado de } \\
\text { São Paulo) }\end{array}$ & $\begin{array}{l}\text { Identificar as concepções } \\
\text { de profissionais de um } \\
\text { centro para o tratamento } \\
\text { dos problemas relacionados } \\
\text { ao uso de álcool e outras } \\
\text { drogas acerca da reabilitação } \\
\text { psicossocial }\end{array}$ \\
\hline 2178 & $\begin{array}{l}\text { Moraes M } \\
\text { (Psicologia) }\end{array}$ & 2008 & $\begin{array}{c}\text { Ciência \& Saúde } \\
\text { Coletiva (BVS) }\end{array}$ & $\begin{array}{c}\text { Modelo de Atenção Integral } \\
\text { à Saúde para Tratamento de } \\
\text { Problemas Decorrentes do } \\
\text { Uso de Álcool e Outras Drogas: } \\
\text { Percepções de Usuários, } \\
\text { Acompanhantes e Profissionais }\end{array}$ & $\begin{array}{l}2 \text { CAPS AD (Recife/ } \\
\text { Pernambuco) }\end{array}$ & $\begin{array}{l}\text { Investigar a percepção de } \\
\text { usuários, acompanhantes } \\
\text { e profissionais, acerca do } \\
\text { modelo de atenção à saúde de } \\
\text { usuários de drogas }\end{array}$ \\
\hline 2279 & $\begin{array}{c}\text { Souza J } \\
\text { (Enfermagem) }\end{array}$ & 2006 & $\begin{array}{l}\text { SMAD, Revista } \\
\text { Eletrônica Saúde } \\
\text { Mental Álcool e } \\
\text { Drogas (BVS) }\end{array}$ & $\begin{array}{l}\text { Vínculos e Redes Sociais de } \\
\text { Indivíduos Dependentes de } \\
\text { Substâncias Psicoativas sob } \\
\text { Tratamento em CAPS AD }\end{array}$ & $\begin{array}{c}\text { CAPS AD (Região Sul } \\
\text { do Brasil) }\end{array}$ & $\begin{array}{l}\text { Identificar as redes sociais e } \\
\text { vínculos estabelecidos por } \\
\text { sujeitos dependentes de } \\
\text { substâncias psicoativas em } \\
\text { tratamento em um CAPS AD }\end{array}$ \\
\hline
\end{tabular}

BVS: Biblioteca Virtual em Saúde; CAPS AD: Centro de Atenção Psicossocial Álcool e Drogas; CAPSi: Centro de Atenção Psicossocial Infantojuvenil; CT: comunidade terapêutica; RAPS: Rede de Atenção Psicossocial; UBS: unidades básica de saúde.

Fonte: elaboração própria.

Esses 22 estudos abordaram serviços de atenção primária em saúde (unidades de saúde e Consultório na Rua) e de atenção especializada (Centros de Atenção Psicossocial Álcool e Drogas - CAPS AD). No Quadro 3 são apresentadas as ações são desenvolvidas em cada local estudado.

A primeira coluna do Quadro 3 diz respeito ao número do estudo; da segunda à quarta estão as ações desenvolvidas, organizadas pelas três dimensões já apresentadas no Quadro 1. Na quinta coluna estão descritas as limitações encontradas em cada serviço. E, na última coluna, o serviço estudado foi categorizado de acordo com a dimensão da construção de autonomia preponderante. 
Quadro 3

Conjunto de ações desenvolvidas pelos estudos.

\begin{tabular}{|c|c|c|c|c|c|}
\hline ESTUDO & RESGATE DE AUTONOMIA & $\begin{array}{c}\text { CONSTRUÇÃO } \\
\text { CORRESPONSÁVEL }\end{array}$ & $\begin{array}{c}\text { DIMENSÃO } \\
\text { SOCIOPOLÍTICA }\end{array}$ & $\begin{array}{c}\text { DIFICULDADES PARA } \\
\text { A AUTONOMIA }\end{array}$ & $\begin{array}{c}\text { DIMENSÃO } \\
\text { PREPONDERANTE }\end{array}$ \\
\hline 1 & $\begin{array}{l}\text { Atendimento em liberdade; } \\
\text { acolhimento e profissional de } \\
\text { referência; PTS; serviço territorial; } \\
\text { realização de grupos e oficinas }\end{array}$ & $\begin{array}{l}\text { Corresponsabilização } \\
\text { no PTS; atividades } \\
\text { territoriais; cuidado } \\
\text { em rede; participação } \\
\text { da família } \\
\end{array}$ & $\begin{array}{l}\text { Iniciativas de geração } \\
\text { de emprego }\end{array}$ & $\begin{array}{c}\text { Estabelecimento } \\
\text { da rede; falta de } \\
\text { profissionais; falta de } \\
\text { estrutura }\end{array}$ & $\begin{array}{c}\text { Construção } \\
\text { corresponsável }\end{array}$ \\
\hline 2 & $\begin{array}{l}\text { Atendimento em liberdade; } \\
\text { acolhimento e profissional de } \\
\text { referência; serviço territorial; } \\
\text { realização de grupos e oficinas }\end{array}$ & - & - & $\begin{array}{l}\text { Abstinência; } \\
\text { estabelecimento da } \\
\text { rede; estigmatização } \\
\text { por profissionais; } \\
\text { falta de profissionais }\end{array}$ & Resgate de autonomia \\
\hline 3 & $\begin{array}{l}\text { Atendimento em liberdade; } \\
\text { acolhimento e profissional de } \\
\text { referência; PTS; serviço territorial }\end{array}$ & $\begin{array}{l}\text { Estratégias de } \\
\text { redução de danos }\end{array}$ & - & $\begin{array}{c}\text { Estigmatização por } \\
\text { profissionais; falta de } \\
\text { profissionais }\end{array}$ & Resgate de autonomia \\
\hline 4 & $\begin{array}{l}\text { Atendimento em liberdade; } \\
\text { acolhimento e profissional de } \\
\text { referência; PTS; serviço territorial; } \\
\text { não obrigatoriedade de abstinência }\end{array}$ & $\begin{array}{l}\text { Corresponsabilização } \\
\text { no PTS; cuidado em } \\
\text { rede; estratégias de } \\
\text { redução de danos }\end{array}$ & - & Falta de estrutura & $\begin{array}{l}\text { Construção } \\
\text { corresponsável }\end{array}$ \\
\hline 5 & $\begin{array}{l}\text { Atendimento em liberdade; } \\
\text { acolhimento e profissional de } \\
\text { referência; serviço territorial; não } \\
\text { obrigatoriedade de abstinência; } \\
\text { realização de grupos e oficinas }\end{array}$ & Cuidado em rede & - & $\begin{array}{l}\text { Estigmatização } \\
\text { por profissionais; } \\
\text { estabelecimento } \\
\text { da rede; falta de } \\
\text { profissionais }\end{array}$ & Resgate de autonomia \\
\hline 6 & $\begin{array}{l}\text { Atendimento em liberdade; } \\
\text { acolhimento e profissional de } \\
\text { referência; serviço territorial; não } \\
\text { obrigatoriedade de abstinência; } \\
\text { realização de grupos e oficinas }\end{array}$ & $\begin{array}{c}\text { Corresponsabilização } \\
\text { no PTS }\end{array}$ & - & $\begin{array}{l}\text { Estabelecimento } \\
\text { da rede; falta de } \\
\text { profissionais; falta de } \\
\text { estrutura }\end{array}$ & Resgate de autonomia \\
\hline 7 & $\begin{array}{l}\text { Atendimento em liberdade; } \\
\text { acolhimento e profissional de } \\
\text { referência; PTS; serviço territorial; } \\
\text { realização de grupos e oficinas }\end{array}$ & $\begin{array}{l}\text { Atividades territoriais; } \\
\text { cuidado em rede }\end{array}$ & $\begin{array}{l}\text { Participação em } \\
\text { associação de } \\
\text { usuários }\end{array}$ & Abstinência & Resgate de autonomia \\
\hline 8 & $\begin{array}{l}\text { Atendimento em liberdade; } \\
\text { acolhimento e profissional de } \\
\text { referência; PTS; serviço territorial; } \\
\text { realização de grupos e oficinas }\end{array}$ & $\begin{array}{l}\text { Corresponsabilização } \\
\text { no PTS; cuidado em } \\
\text { rede }\end{array}$ & - & $\begin{array}{l}\text { Estabelecimento } \\
\text { da rede; falta de } \\
\text { estrutura }\end{array}$ & Resgate de autonomia \\
\hline 9 & $\begin{array}{l}\text { Atendimento em liberdade; } \\
\text { acolhimento e profissional de } \\
\text { referência; PTS; serviço territorial; } \\
\text { realização de grupos e oficinas }\end{array}$ & - & - & $\begin{array}{l}\text { Estabelecimento da } \\
\text { rede }\end{array}$ & Resgate de autonomia \\
\hline 10 & $\begin{array}{l}\text { Atendimento em liberdade; } \\
\text { acolhimento e profissional } \\
\text { de referência; PTS; serviço } \\
\text { territorial; não obrigatoriedade de } \\
\text { abstinência; realização de grupos } \\
\text { e oficinas }\end{array}$ & $\begin{array}{c}\text { Corresponsabilização } \\
\text { no PTS; participação } \\
\text { da família; estratégias } \\
\text { de redução de danos }\end{array}$ & $\begin{array}{l}\text { Iniciativas de geração } \\
\text { de emprego }\end{array}$ & $\begin{array}{l}\text { Estabelecimento } \\
\text { da rede; falta de } \\
\text { profissionais; falta de } \\
\text { estrutura }\end{array}$ & Resgate de autonomia \\
\hline
\end{tabular}

(continua) 
Quadro 3 (continuação)

\begin{tabular}{|c|c|c|c|c|c|}
\hline ESTUDO & RESGATE DE AUTONOMIA & $\begin{array}{c}\text { CONSTRUÇÃO } \\
\text { CORRESPONSÁVEL }\end{array}$ & $\begin{array}{c}\text { DIMENSÃO } \\
\text { SOCIOPOLÍTICA }\end{array}$ & $\begin{array}{l}\text { DIFICULDADES PARA } \\
\text { A AUTONOMIA }\end{array}$ & $\begin{array}{c}\text { DIMENSÃO } \\
\text { PREPONDERANTE }\end{array}$ \\
\hline 11 & $\begin{array}{l}\text { Atendimento em liberdade; } \\
\text { acolhimento e profissional de } \\
\text { referência; PTS; serviço territorial; } \\
\text { realização de grupos e oficinas }\end{array}$ & $\begin{array}{l}\text { Corresponsabilização } \\
\text { no PTS; participação } \\
\text { da família; estratégias } \\
\text { de redução de danos }\end{array}$ & - & $\begin{array}{l}\text { Abstinência; } \\
\text { estabelecimento } \\
\text { da rede; falta de } \\
\text { profissionais }\end{array}$ & Resgate de autonomia \\
\hline 12 & $\begin{array}{l}\text { Atendimento em liberdade; } \\
\text { acolhimento e profissional } \\
\text { de referência; PTS; serviço } \\
\text { territorial; não obrigatoriedade de } \\
\text { abstinência; realização de grupos } \\
\text { e oficinas }\end{array}$ & $\begin{array}{l}\text { Corresponsabilização } \\
\text { no PTS; participação } \\
\text { da família }\end{array}$ & - & $\begin{array}{l}\text { Estabelecimento da } \\
\text { rede }\end{array}$ & Resgate de autonomia \\
\hline 13 & $\begin{array}{l}\text { Atendimento em liberdade; } \\
\text { acolhimento e profissional de } \\
\text { referência; PTS; serviço territorial; } \\
\text { realização de grupos e oficinas }\end{array}$ & - & - & $\begin{array}{l}\text { Abstinência; } \\
\text { estabelecimento da } \\
\text { rede; estigmatização } \\
\text { por profissionais; } \\
\text { falta de profissionais; } \\
\text { falta de estrutura }\end{array}$ & Resgate de autonomia \\
\hline 14 & $\begin{array}{l}\text { Atendimento em liberdade; } \\
\text { acolhimento e profissional } \\
\text { de referência; PTS; serviço } \\
\text { territorial; não obrigatoriedade de } \\
\text { abstinência; realização de grupos } \\
\text { e oficinas }\end{array}$ & $\begin{array}{l}\text { Corresponsabilização } \\
\text { no PTS; atividades } \\
\text { territoriais; cuidado } \\
\text { em rede }\end{array}$ & - & $\begin{array}{l}\text { Estabelecimento da } \\
\text { rede }\end{array}$ & $\begin{array}{l}\text { Construção } \\
\text { corresponsável }\end{array}$ \\
\hline 15 & $\begin{array}{l}\text { Atendimento em liberdade; } \\
\text { acolhimento e profissional } \\
\text { de referência; PTS; serviço } \\
\text { territorial; não obrigatoriedade de } \\
\text { abstinência; realização de grupos } \\
\text { e oficinas }\end{array}$ & $\begin{array}{l}\text { Corresponsabilização } \\
\text { no PTS; estratégias de } \\
\text { redução de danos }\end{array}$ & - & Falta de profissionais & $\begin{array}{l}\text { Construção } \\
\text { corresponsável }\end{array}$ \\
\hline 16 & $\begin{array}{c}\text { Atendimento em liberdade; } \\
\text { acolhimento e profissional } \\
\text { de referência; PTS; serviço } \\
\text { territorial; não obrigatoriedade de } \\
\text { abstinência; realização de grupos } \\
\text { e oficinas }\end{array}$ & $\begin{array}{l}\text { Corresponsabilização } \\
\text { no PTS; estratégias de } \\
\text { redução de danos }\end{array}$ & $\begin{array}{l}\text { Participação em } \\
\text { associação de } \\
\text { usuários }\end{array}$ & $\begin{array}{l}\text { Abstinência; } \\
\text { estabelecimento da } \\
\text { rede }\end{array}$ & Resgate de autonomia \\
\hline 17 & $\begin{array}{l}\text { Atendimento em liberdade; } \\
\text { acolhimento e profissional } \\
\text { de referência; PTS; serviço } \\
\text { territorial; não obrigatoriedade de } \\
\text { abstinência; realização de grupos } \\
\text { e oficinas }\end{array}$ & $\begin{array}{l}\text { Corresponsabilização } \\
\text { no PTS; cuidado em } \\
\text { rede; estratégias de } \\
\text { redução de danos }\end{array}$ & - & $\begin{array}{l}\text { Estabelecimento da } \\
\text { rede }\end{array}$ & $\begin{array}{l}\text { Construção } \\
\text { corresponsável }\end{array}$ \\
\hline 18 & $\begin{array}{l}\text { Atendimento em liberdade; } \\
\text { acolhimento e profissional de } \\
\text { referência; PTS; serviço territorial; } \\
\text { realização de grupos e oficinas }\end{array}$ & Cuidado em rede & - & $\begin{array}{l}\text { Estabelecimento da } \\
\text { rede }\end{array}$ & Resgate de autonomia \\
\hline
\end{tabular}

(continua) 


\begin{tabular}{|c|c|c|c|c|c|}
\hline ESTUDO & RESGATE DE AUTONOMIA & $\begin{array}{c}\text { CONSTRUÇÃO } \\
\text { CORRESPONSÁVEL }\end{array}$ & $\begin{array}{c}\text { DIMENSÃO } \\
\text { SOCIOPOLÍTICA }\end{array}$ & $\begin{array}{c}\text { DIFICULDADES PARA } \\
\text { A AUTONOMIA }\end{array}$ & $\begin{array}{c}\text { DIMENSÃO } \\
\text { PREPONDERANTE }\end{array}$ \\
\hline 19 & $\begin{array}{l}\text { Atendimento em liberdade; } \\
\text { acolhimento e profissional } \\
\text { de referência; PTS; serviço } \\
\text { territorial; não obrigatoriedade de } \\
\text { abstinência; realização de grupos } \\
\text { e oficinas }\end{array}$ & $\begin{array}{l}\text { Corresponsabilização } \\
\text { no PTS; estratégias de } \\
\text { redução de danos }\end{array}$ & - & $\begin{array}{c}\text { Estabelecimento } \\
\text { da rede; falta de } \\
\text { profissionais; falta de } \\
\text { estrutura }\end{array}$ & $\begin{array}{l}\text { Construção } \\
\text { corresponsável }\end{array}$ \\
\hline 20 & $\begin{array}{l}\text { Atendimento em liberdade; } \\
\text { acolhimento e profissional de } \\
\text { referência; PTS; serviço territorial; } \\
\text { realização de grupos e oficinas }\end{array}$ & $\begin{array}{c}\text { Corresponsabilização } \\
\text { no PTS; atividades } \\
\text { territoriais }\end{array}$ & $\begin{array}{c}\text { Iniciativas de geração } \\
\text { de emprego }\end{array}$ & $\begin{array}{l}\text { Estabelecimento da } \\
\text { rede }\end{array}$ & Resgate de autonomia \\
\hline 21 & $\begin{array}{l}\text { Atendimento em liberdade; } \\
\text { acolhimento e profissional de } \\
\text { referência; serviço territorial; } \\
\text { realização de grupos e oficinas }\end{array}$ & $\begin{array}{c}\text { Cuidado em rede; } \\
\text { participação da } \\
\text { família }\end{array}$ & - & $\begin{array}{c}\text { Abstinência; } \\
\text { estigmatização } \\
\text { por profissionais; } \\
\text { estabelecimento } \\
\text { da rede; falta de } \\
\text { profissionais; falta de } \\
\text { estrutura }\end{array}$ & Resgate de autonomia \\
\hline 22 & $\begin{array}{l}\text { Atendimento em liberdade; } \\
\text { acolhimento e profissional de } \\
\text { referência; serviço territorial; } \\
\text { realização de grupos e oficinas }\end{array}$ & - & - & $\begin{array}{c}\text { Estabelecimento } \\
\text { da rede; falta de } \\
\text { profissionais; falta de } \\
\text { estrutura }\end{array}$ & Resgate de autonomia \\
\hline
\end{tabular}

PTS: projeto terapêutico singular.

Fonte: elaboração própria.

A partir dos resultados encontrados nessa revisão, elaboramos a descrição do conjunto das ações relativas à construção de autonomia que de fato vêm ocorrendo nos serviços estudados, bem como suas limitações, que foi o objetivo proposto. Isso possibilita destacar características da RAPS que vêm promovendo avanços ou retrocessos acerca desse processo.

Dentre as ações que sobressaem, estão as relativas à primeira dimensão, a da singularidade: resgate de autonomia no processo terapêutico. Essas ações, isto é, o cuidado em liberdade, o acolhimento e profissional de referência, o desenvolvimento do projeto terapêutico singular (PTS), o atendimento em serviço territorial e a realização de grupos e oficinas foram encontradas para a maioria dos serviços. A não obrigatoriedade da abstinência foi a menos assinalada (11 estudos). Há também algumas ações relativas à segunda dimensão que constam em muitos serviços, como o fomento à corresponsabilização no processo terapêutico (13 estudos), o cuidado conjunto a outros dispositivos da rede (9 estudos) e as estratégias/oficinas de redução de danos (8 estudos).

Na dimensão da construção de autonomia em âmbito sociopolítico, quase não houve ações assinaladas, sendo somente cinco em serviços diferentes (iniciativas de trabalho/geração de renda e participação em associação de usuários, três e duas vezes, respectivamente). As dificuldades ou os limites para desenvolver a construção de autonomia, entretanto, foram assinalados em todos os serviços, destacando-se as dificuldades na "relação com dispositivos da rede intersetorial/falta de rede" e "falta de profissionais ou capacitação profissional”, mencionados em 18 e 12 estudos, respectivamente.

Assim, os estudos mostram que há importantes serviços consolidados no país, promovendo diversas ações de cuidado, com vistas a construir a autonomia dos sujeitos por meio do cuidado em saúde. Há um conjunto de práticas coeso às bases teóricas do paradigma psicossocial que os fundamentam. Entretanto em muitos ainda se preza pela abstinência e ocorre uma compreensão limitada dessas 
bases teóricas pelos profissionais. Constituem essas ações os serviços territoriais, funcionando de portas abertas e promulgando o cuidado em liberdade, por meio de equipes interdisciplinares.

Resguardando as especificidades de cada serviço (CAPS AD e os de atenção primária), a maioria dos serviços analisados desenvolvem tais ações, sendo que essas demonstram ser primordiais para que os usuários os considerem locais de cuidado e nos quais possam depositar confiança, de maneira que haja tanto o acolhimento das necessidades imediatas de saúde quanto o acompanhamento contínuo.

Entretanto a estratégia de construção de autonomia para o paradigma psicossocial não deve se realizar somente no interior dos serviços. Estes detêm sua imersão geográfica no território justamente para articulá-lo, descobrir e intensificar vínculos já estabelecidos, bem como criar novas possibilidades de redes de apoio, dispositivos de garantia de direitos, de lazer, arte e cultura 31,33. Ainda, devem articular ações de geração de emprego e renda aos dispositivos da RAPS e integrar as famílias dos usuários nas instituições concernentes ao processo terapêutico. Isso possibilita que o usuário, que muitas vezes tem de lidar com a estigmatização, possa fazer parte do meio social para desenvolver essa autonomia proporcionada pelo resgate de valor e autocuidado ocorrido no interior dos serviços 21 .

Assim, observando-se o quadro de sistematização das ações e considerando-se as reflexões anteriores, verifica-se que as ações de uma autonomia relacional decaem em relação às ações da dimensão da valorização da singularidade. A estratégia de construção de autonomia na dimensão sociopolítica, que é a do desenvolvimento de cidadania no seio da sociedade, é praticamente inexistente.

Portanto as ações dos serviços que os usuários expressam que desenvolvem sua autonomia, como o acolhimento, o PTS e os grupos de caráter não obrigatório, ganham destaque e representam imenso avanço em comparação às abordagens baseadas na reclusão e objetificação. Isso está de acordo com que mencionam outros autores - que os usuários se sentem acolhidos e num processo de cuidado territorial, com projetos terapêuticos adequados 34,35. A noção de respeito às escolhas e, também, as características da segunda dimensão de autonomia, como o cuidado em rede, possibilitam a corresponsabilidade do tratamento, o que preconiza a literatura 17,18 .

A não obrigação é um fator importante também para que o processo terapêutico se desenvolva, pois permite a continuidade de vínculos, algo que transcorre muito no atendimento aos usuários pelo Consultório na Rua 36,37. E a própria noção de conquista de seu espaço e vínculos, mesmo que em condições que tragam vulnerabilidades, demonstra que os indivíduos têm receio de retornar a uma vida que também detinha muitas dificuldades, como relações familiares violentas, vínculos empregatícios adoecedores, pobreza etc. 36,38 .

Assim, quando a abordagem aos usuários constrói vínculos de confiança, eles reconhecem a importância do serviço, pois profissionais e usuários relatam, nos estudos abordados, que a estigmatização devido ao uso abusivo é real e acarreta perdas concretas, como de emprego, vínculos familiares, bens materiais, para além das dificuldades de saúde, fazendo que os usuários queiram aderir ao processo terapêutico. Isto é, respeito e construção corresponsável são preceitos fundamentais, como preponderam Onocko-Campos \& Campos 32.

Outra ação importante vinculada à valorização do usuário e à corresponsabilidade é a organização coletiva do serviço 20,39,40. Exemplos são as discussões em assembleias, o desenvolvimento conjunto de oficinas nas quais os próprios usuários podem resgatar e compartilhar seus valores e conhecimentos (sobre música, poesia e outras artes, trabalhos com informática, marcenaria, fotografia etc.), o desenvolvimento de eventos, como seminários (sobre saúde e drogas, sobre a cidade e o território) e eventos comemorativos (o dia de luta antimanicomial, festa junina, Carnaval etc.). Entretanto são ações muito pouco executadas, conforme evidenciado no quadro de sistematização e também encontrado em demais estudos 41,42,43.

Destacam-se ainda os grupos que abordam a redução de danos, nos quais há a educação coletiva sobre as drogas e a relação com os cuidados de saúde e redução de riscos sociais, com compartilhamento inclusive dos conhecimentos dos próprios usuários. Eles compartilham não só as experiências com o uso de drogas, mas também sobre dificuldades no território, violência e acesso à saúde 44 . Os grupos são especialmente importantes nas unidades de saúde, nas quais o acompanhamento dificilmente ocorre cotidianamente ou várias vezes na semana. Assim, esses grupos possibilitam superar certas iniquidades em saúde, também aumentando o grau de autoestima e autonomia nos processos de vida diários 45 . 
A noção da autonomia relacional é também destacada nos estudos por meio da imersão dos usuários numa rede de apoio externa, inclusive porque, mesmo indo aos serviços, eles não deixam de ter uma rede territorial de vínculos 46,47. Porém é uma dimensão que enfrenta muitas dificuldades, tanto pela falta de relação entre os dispositivos da rede quanto pela dificuldade de os profissionais estarem no território fortalecendo vínculos já estabelecidos. Ressalta-se a necessidade de envolvimento da família por meio de associações e dos centros de convivência, bem como a ligação com instituições educacionais (sobretudo para os adolescentes), mas são ações que tampouco ocorrem nos serviços estudados. O que se aproxima disso é a atuação dos profissionais dos NASF e ACS 48,49.

Logo, a falta de políticas relativas a trabalho e renda, moradia, ausência de associações de usuários e familiares, de iniciativas culturais territoriais nas quais os usuários sejam protagonistas e as intervenções violentas no território por parte do poder público representam a principal barreira, um evidente limite da construção de autonomia pelas redes nas quais os dispositivos estão inseridos. E, se levamos em conta a construção de autonomia enquanto processo, podemos considerar que neste existe uma lacuna. Como desenvolvido por Jervis 50 e Sena 34, o desenvolvimento de uma cidadania concreta ocorre na comunidade e sociedade em que as pessoas vivem e nas quais são marginalizadas.

Essa lacuna é significativamente aumentada com a ausência de formação continuada em saúde nos preceitos e ações do paradigma psicossocial, em especial a redução de danos, impossibilitando, por exemplo, o desenvolvimento das oficinas de redução de danos 51,52. Disso decorre, também, a falta de crítica pelos profissionais adiante da centralidade dos diagnósticos e da noção de combate às drogas, o que acarreta a objetificação dos usuários e o foco do tratamento na desintoxicação e na abstinência 53,54. Evidentemente, é necessário expressar que isso é também decorrência da dificuldade em se trabalhar em equipes limitadas em número de profissionais e em serviços precários, conforme apontam Bittencourt et al. 37 e Conejo 55 .

Por fim, é possível considerar que a construção de vínculos corresponsáveis, ou seja, a efetiva participação dos usuários, assinalada em 13 estudos, fortalece a noção de processo terapêutico, como trazem Ongaro-Basaglia 56 e Basaglia 57. Pois, ao mesmo tempo em que diminui a diferença de poder entre usuários e técnicos de saúde, promove a construção de poder contratual, ou seja, resgata valores de modo que se construa maior autoconfiança para desenvolver vínculos inclusive fora dos "espaços de tratamento". Contudo, o desenvolvimento de vínculos externos, a dimensão da cidadania e da reinserção social, com participação nos processos de trocas coletivas - econômicas, políticas, afetivas - é limitado pelo conjunto de dificuldades já abordado.

Essas limitações, portanto, muitas vezes impossibilitam uma transformação prática da vida dos usuários, fazendo-os dependentes dos CAPS e unidades de saúde, reoxigenando o processo conhecido como revolving-door ou carreira de internamento 21. Isto é, a falta de uma rede de serviços e profissionais preparada para continuar processos terapêuticos, bem como a não transformação das condições de reprodução da vida diária dos usuários, que faz que estes muitas vezes retornem ao mesmo local de tratamento, com as mesmas demandas 58,59,60,61.

Pode-se compreender que essas dificuldades acarretam um limite para o desenvolvimento do projeto da reforma psiquiátrica como um todo. Pois ela, em suas bases prático-conceptuais - como a psiquiatria da desinstitucionalização 20,50 - buscara criar e proporcionar o desenvolvimento de uma rede territorial concreta, com dispositivos diversos espalhados pela cidade, tais como moradias, cooperativas de trabalho e associações para produção sociocultural e expressão política. Elementos que segundo Rotelli 21 (p. 95) são o objetivo e a prática da instituição inventada, que buscam o "reingressar no corpo social, consumo e produção, trocas, novos papéis, outros modos materiais de ser para o outro, aos olhos do outro".

Assim como são limites para a redução de danos, que se baseia no desenvolvimento de grupos de ajuda por pares e intervenções de autocuidado que são realizadas nos territórios pelos próprios usuários - tal como se desenvolve em outros países. Essas e outras ações são destacadas pelo estudo global sobre redução de danos de 2018 da instituição holandesa Mainline 62. Dentre essas ações se notabiliza a necessidade de combater a pobreza, a violência com os usuários, o acesso precário à moradia e a oferta de serviços de aconselhamento e uso seguro 44,62. 


\section{Considerações finais}

Os resultados desta revisão evidenciam um conjunto de estratégias de construção de autonomia contraditório e difuso. Existem ações que constroem autonomia e outras que asseveram o controle sobre os usuários. Apesar da atualidade desta revisão, que aborda diferentes serviços de um novo paradigma no cuidado a usuários de drogas, os resultados apontam que continua a ocorrer a sobreposição da razão biomédica sobre o que é considerado o desvio, o descontrole, a loucura.

Identificou-se a falta de participação dos usuários na organização dos serviços, os quais detêm regras impostas, mesmo que haja certa autonomia para participação de grupos e oficinas e a ocorrência de projetos terapêuticos singulares. Ainda, o conjunto de ações para construção de autonomia se realiza no interior desses serviços. Isto é, quase não existem ações intersetoriais tampouco participação em instâncias comunitárias e políticas, como associações de usuários e conselhos de saúde e assistência social. O que a literatura pesquisada demonstra é que ainda existe a preponderância da dimensão individual, velada e organizada, mesmo que com a ideia de tratamento terapêutico, em detrimento da corresponsabilidade e, sobretudo da participação sociopolítica.

Notabiliza-se que, mesmo que existam na rede brasileira dispositivos de acolhimento temporário e reinserção social para além dos CAPS, tais como os centros de convivência e as unidades de acolhimento, estes não estão sendo desenvolvidos e utilizados como preconiza a política de cuidado. São serviços cruciais para a construção de autonomia e o combate à estigmatização e marginalização dos usuários de drogas, mas esta revisão não evidencia sua inserção, asseverando a carência de uma intersetorialidade efetiva pela própria RAPS. Logo, o papel central dos CAPS, de realizar o matriciamento junto aos demais dispositivos, tampouco tem ocorrido como preconiza a política de saúde mental e drogas.

Ainda assim, as ações específicas desenvolvidas por CAPS AD e serviços de atenção primária demonstram ser fundamentais para ocorrer o início do resgate de autonomia e valorização dos usuários diante da estigmatização e marginalização. O trabalho de equipes dos NASF, dos ACS e dos Consultórios na Rua possibilita um cuidado muito próximo à realidade dos usuários e de suas famílias, garante certos direitos, a mediação de conflitos familiares e, por vezes, o acolhimento com base na redução de danos. Esse conjunto possibilita o acompanhamento em saúde que muitas vezes é dificultado pelo receio dos usuários em acessarem os serviços pelo simples fato de utilizarem drogas, o que demonstra a intensidade do preconceito e do estigma que ainda enfrentam no seu cotidiano.

O cuidado sendo realizado no espaço interno, institucional, aliado à carência da intersetorialidade, reforça a dependência que a própria política cria para os usuários em torno de serviços específicos. $\mathrm{O}$ espaço da reclusão que era reservado para o considerado viciado foi expandido, mas continua a ser separado do convívio social e nele a instituição psiquiátrica ainda dita as palavras e ações com os quais se permite se expressar e viver. As necessidades das pessoas em tratamento são abordadas de forma fragmentada, ao invés de serem integralizadas, como preconiza o sistema de saúde, levando a RAPS a promover uma capilarização das formas de controle, perpetuando em parte a lógica cronificante das instituições totais.

Fica evidente, a partir desta revisão, que, para que ocorra a diretriz da estratégia de construção de autonomia, é necessário maior investimento na RAPS, para ocorrer de fato o combate à marginalização dos usuários que fazem uso abusivo de drogas. Para além dos CAPS e das unidades de saúde, é necessário investir nos dispositivos que favoreçam a promoção da saúde com moradia de qualidade, emprego, possibilidades de se apropriar do que o ser humano já produziu, para além de vidas marcadas pelos impactos de uma sociedade que adoece.

É necessário apoiar a construção dessa lógica de cuidado em nível social, em uma sociedade que receba e construa, junto ao excluído, condições materiais com as quais este possa reconstituir sua vida. Os dispositivos e as ações de cuidado, mais do que estarem geograficamente fora dos muros brancos e intransponíveis das instituições totais, devem fazer parte da transformação social, constantemente em busca de autonomia. 


\section{Colaboradores}

M. E. R. Martins elaborou o conteúdo do artigo. F. Büchele e C. C. Bolsoni contribuíram na revisão. Todos os autores aprovaram a versão final do artigo.

\section{Informações adicionais}

ORCID: Matheus Eduardo Rodrigues Martins (0000-0002-4761-9252); Fatima Buchele (00000002-4661-9031); Carolina Carvalho Bolsoni (0000-0003-1246-0218).

\section{Referências}

1. Ministério da Saúde. A política do Ministério da Saúde para atenção integral a usuários de álcool e outras drogas. Brasília: Ministério da Saúde; 2003.

2. Soares CB. Consumo contemporâneo de drogas e juventude: a construção do objeto na perspectiva da saúde coletiva [Tese de LivreDocência]. São Paulo: Departamento de Enfermagem em Saúde Coletiva, Escola de Enfermagem, Universidade de São Paulo; 2007.

3. Machado 1, Boarini M. Políticas sobre drogas no Brasil: a estratégia de redução de danos. Psicol Ciênc Prof 2013; 33:580-95.

4. Souza DR, Oliveira MAF, Soares RH, Domanico A, Pinho PH. Resistências dos profissionais da atenção psicossocial em álcool/drogas à abordagem de redução de danos. J Nurs Health 2017; 7:16-24.

5. Medeiros PFP, Garcia LSL, Kinoshita RT, Santos PS, Hayashida G. Rede de Atenção Psicossocial no Sistema Único de Saúde (SUS): Eixo Políticas e Fundamentos. Brasília: Secretaria Nacional de Políticas sobre Drogas; 2017.

6. Santos V, Soares CB. O consumo de substâncias psicoativas na perspectiva da saúde coletiva: uma reflexão sobre valores sociais e fetichismo. Saúde Transform Soc 2013; 4:38-54.

7. Brites C. Política de drogas no Brasil: usos e abusos. In: Bokany V, organizadora. Drogas no Brasil: entre a saúde e a justiça. Proximidades e opiniões. São Paulo: Editora Fundação Perseu Abramo; 2015. p. 119-42.

8. Passos E, Souza T. Redução de danos e saúde pública: construções alternativas à política global de "guerra às drogas". Psicol Soc 2011; 23:154-62.

9. Teixeira M, Ramôa ML, Engstrom E, Ribeiro JM. Tensões paradigmáticas nas políticas públicas sobre drogas: análise da legislação brasileira no período de 2000 a 2016. Ciênc Saúde Colet 2017; 22:1455-66.

10. Hornstein C. Guerra às drogas: "por que não tentar diferente depois de tanto fracasso?". Carta Maior 2014; 14 mai. https://www.cartamaior. com.br/?/Editoria/Direitos-Humanos/ Guerra-as-drogas-por-que-nao-tentar-o-dife rente-depois-de-tanto-fracasso-/5/30923.

11. Gomes-Medeiros D, Faria PH, Campos GWS, Tófoli LF. Política de drogas e Saúde Coletiva: diálogos necessários. Cad Saúde Pública 2019; 35:e00242618.
12. Paim JS, Almeida Filho N. A crise da saúde pública e a utopia da saúde coletiva. Salvador: Casa da Qualidade Editora; 2000.

13. Buss PM. Promoção da saúde e qualidade de vida. Ciênc Saúde Colet 2000; 5:163-77.

14. Campos GW, Barros RB, Castro AM. Avaliação de política nacional de promoção da saúde. Ciênc Saúde Colet 2004; 9:745-9.

15. Czeresnia D. O conceito de saúde e a diferença entre prevenção e promoção. In: Czeresnia D, Freitas CM, organizadores. Promoção da saúde: conceitos, reflexões, tendências. Rio de Janeiro: Editora Fiocruz; 2003. p. 43-58.

16. Fleury-Teixeira P, Vaz FA, Campos FC, Alvares J, Oliveira V, Aguiar R. Autonomia como categoria central no conceito de promoção de saúde. Ciênc Saúde Colet 2008; 13 Suppl 2:2115-22.

17. Kinoshita RT. Contratualidade e reabilitação psicossocial. In: Pitta A, organizador. Reabilitação psicossocial no Brasil. 2a Ed. São Paulo: Hucitec Editora; 2001. p. 55-9.

18. Merhy EE. Em busca do tempo perdido: a micropolítica do trabalho vivo em saúde. In: Merhy EE, Onocko R, organizadores. Agir em saúde: um desafio para o público. 2a Ed. São Paulo: Hucitec Editora; 2002. p. 71-112.

19. Amarante PDC. Avaliação dos novos serviços de saúde mental: em busca de novos parâmetros. Saúde Debate 1996; 52:74-83.

20. Basaglia F. As instituições da violência. In: Basaglia F, organizador. A instituição negada. Rio de Janeiro: Edições Graal; 1985. p. 99-134.

21. Rotelli F. A instituição inventada. In: Rotelli F, Leonardis O, Mauri D, Risio C, organizadores. Desinstitucionalização. São Paulo: Hucitec Editora; 1990. p. 89-99.

22. Ribeiro FML, Minayo MCS. As mudanças na política brasileira de drogas: o avanço da lógica da justiça sobre a saúde. Revista Cultura y Droga 2020; 25:17-39.

23. Massuda A. Mudanças no financiamento da atenção primária à saúde no sistema de saúde brasileiro: avanço ou retrocesso? Ciênc Saúde Colet 2020; 25:1181-8.

24. Silva T, Soares AN, Lacerda GA, Mesquita JF, Silveira DC. Política Nacional de Atenção Básica 2017: implicações no trabalho do agente comunitário de saúde. Saúde Debate 2020; 44:58-69.

25. Ercole FF, Melo LS, Alcoforado CC. Revisão integrativa versus revisão sistemática. REME Rev Min Enferm 2014; 18:9-12. 
26. Souza MT, Silva M, Carvalho R. Revisão integrativa: o que é e como fazer. Einstein (São Paulo) 2010; 8:102-6.

27. Soares CB, Hoga LA, Peduzzi M, Sangaleti C, Yonekura T, Silva DR. Revisão integrativa: conceitos e métodos utilizados na enfermagem. Rev Esc Enferm USP 2014; 48:335-45.

28. Stetler CB, Morsi D, Rucki S, Broughton S, Corrigan B, Fitzgerald J, et al. Utilization-focused integrative reviews in a nursing service. Appl Nurs Res 1998; 11:195-206.

29. Minayo MC. O desafio do conhecimento: pesquisa qualitativa em saúde. 11a Ed. São Paulo: Hucitec Editora; 2008.

30. Ministério da Saúde. Portaria no 3.088, de 23 de dezembro de 2011. Institui a Rede de Atenção Psicossocial para pessoas com sofrimento ou transtorno mental e com necessidades decorrentes do uso de crack, álcool e outras drogas, no âmbito do Sistema Único de Saúde (SUS). Diário Oficial da União 2013; 21 mai.

31. Yasui S. Rupturas e encontros: desafios da reforma psiquiátrica brasileira [Tese de Doutorado]. Rio de Janeiro: Escola Nacional de Saúde Pública Sergio Arouca, Fundação Oswaldo Cruz; 2006.

32. Onocko-Campos R, Campos GWS. Co-construção de autonomia: o sujeito em questão. In: Campos GWS, Minayo MCS, Akerman M, Drumond JM, Carvalho YM, organizadores. Tratado de saúde coletiva. São Paulo: Hucitec Editora/Rio de Janeiro: Editora Fiocruz; 2006. p. 669-88.

33. Amarante P, Lancetti A. Saúde mental e saúde coletiva. In: Campos GWS, Minayo MCS, Akerman M, Drumond JM, Carvalho YM, organizadores. Tratado de saúde coletiva. São Paulo: Hucitec Editora/Rio de Janeiro: Editora Fiocruz; 2006. p. 615-34.

34. Sena J. Produção do cuidado no Centro de Atenção Psicossocial de Fortaleza - CE: limites e desafios na construção da autonomia do usuário [Dissertação de Mestrado]. Fortaleza: Universidade Estadual do Ceará; 2010.

35. Borges CD, Schneider DR. Trajetória do cuidado e o percurso ao CAPSad: com a palavra os usuários. Cadernos Brasileiros de Saúde Mental 2018; 10:224-49.

36. Londero M, Ceccim R, Bilibio L. Consultório de/na Rua: desafio para um cuidado em verso na saúde. Interface (Botucatu) 2014; 18:251-60.

37. Bittencourt M, Pantoja PVN, Silva Júnior PCB, Pena JLC, Nemer RCB, Moreira R. Consultório na Rua: as práticas de cuidado com usuários de álcool e outras drogas em Macapá. Esc Anna Nery Rev Enferm 2019; 23:e20180261.

38. Paula M, Jorge MB, Vasconcelos M, Albuquerque R. Assistência ao usuário de drogas na atenção primária à saúde. Psicol Estud 2014; 19:223-33.

39. Saraceno B. Libertando identidades: da reabilitação psicossocial à cidadania possível. Rio de Janeiro: Instituto Basaglia/Te Cora; 2001.

40. Junqueira A, Carniel IC, Mantovani A. As assembleias como possibilidades de cuidado em saúde mental em um CAPs. Vínculo 2015; 12:31-40.
41. Godoy MC, Viana A, Vasconcelos K, Bonvini O. O compartilhamento do cuidado em saúde mental: uma experiência de cogestão de um centro de atenção psicossocial em Fortaleza, CE, apoiada em abordagens psicossociais. Saúde Soc 2012; 21 Suppl 1:152-63.

42. Martins J. CAPS AD III entre a cor cinza da técnico-burocracia e as cores vibrantes que articulam clínica e política [Dissertação de Mestrado]. São Cristóvão: Universidade Federal de Sergipe; 2015.

43. Tibiriçá V, Luchini E, Almeida C. Perspectiva do usuário de drogas sobre seu tratamento e a rede de atenção psicossocial. SMAD, Rev Eletrônica Saúde Mental Álcool Drog 2019; 15:1-9.

44. Gomes T, Vecchia MD. Estratégias de redução de danos no uso prejudicial de álcool e outras drogas: revisão de literatura. Ciênc Saúde Colet 2018; 23:2327-38.

45. Vasconcelos SC, Frazão I, Vasconcelos E, Cavalcanti A, Monteiro E, Ramos V. Demandas de autocuidado em grupo terapêutico: educação em saúde com usuários de substâncias psicoativas. Rev Enferm UERJ 2013; 21:79-83.

46. Lacerda A. Redes de apoio social no Sistema da Dádiva: um novo olhar sobre a integralidade do cuidado no cotidiano de trabalho do agente comunitário de saúde [Tese de Doutorado]. Rio de Janeiro: Escola Nacional de Saúde Pública Sergio Arouca, Fundação Oswaldo Cruz; 2010.

47. Peiter P, Belmonte P, Teixeira M, Cobra G, Lacerda A. Homeless crack cocaine users: territories and territorialities in the constitution of social support networks for health. Soc Sci Med 2019; 227:111-8.

48. Oliveira EM, Santos NTV. A rede de assistência aos usuários de álcool e outras drogas: em busca da integralidade. In: Santos LMB, organizador. Outras palavras sobre o cuidado de pessoas que usam drogas. Porto Alegre: Conselho Regional de Psicologia do Rio Grande do Sul; 2010. p. 71-86.

49. Cardoso MP, Agnoll R, Taccolini C, Tansini K, Vieira A, Hirdes A. A percepção dos usuários sobre a abordagem de álcool e outras drogas na atenção primária à saúde. Aletheia 2014; (45):72-86.

50. Jervis G. Manuale critico di psichiatria. Milano: Feltrinelli; 1975

51. Coelho HV, Soares CB. Práticas na atenção básica voltadas para o consumo prejudicial de drogas. Rev Esc Enferm USP 2014; 48:111-9.

52. Engstrom EM, Teixeira MB. Equipe "Consultório na Rua” de Manguinhos, Rio de Janeiro, Brasil: práticas de cuidado e promoção da saúde em um território vulnerável. Ciênc Saúde Colet 2016; 21:1839-48.

53. Rosenstock KIV, Neves MJ. Papel do enfermeiro da atenção básica de saúde na abordagem ao dependente de drogas em João Pessoa, PB, Brasil. Rev Bras Enferm 2010; 63:581-6.

54. Lima A, Dimenstein M, Macedo JP. Consumo de álcool e drogas e o trabalho do psicólogo no núcleo de apoio à saúde da família. Psicol Pesq 2015; 9:188-97. 
55. Conejo SP, Lisboa VC, Oliveira A, Garcia MR. Contribuindo para a construção da autonomia com profissionais que atuam com usuários de drogas: uma análise de dois projetos de intervenção no maior polo manicomial do Brasil. In: Garcia MV, Conejo SP, Melo TM, organizadores. Drogas e direitos humanos: caminhos e cuidados. Holambra: Editora Setembro; 2017. p. 17-44.

56. Ongaro-Basaglia F. Rovesciamento istituzionale e finalità comune. In: Basaglia $\mathrm{F}$, organizador. L'istituzione negata. Milano: Baldini Castoldi; 2018. p. 321-35.

57. Basaglia F. A utopia da realidade. In: Amarante $\mathrm{P}$, organizador. Escritos selecionados em saúde mental e reforma psiquiátrica. Rio de Janeiro: Garamond; 2010. p. 225-36.

58. Wandekoken K, Quintanilha B, Dalbello-Araujo M. Biopolítica na assistência aos usuários de álcool e outras drogas. Rev Subj 2015; 15:389-97.

59. Lacerda C, Fuentes-Rojas M. Significados e sentidos atribuídos ao Centro de Atenção Psicossocial Álcool e outras Drogas (CAPS AD) por seus usuários: um estudo de caso. Interface (Botucatu) 2017; 21:363-72.

60. Silva L, Almeida A, Amato T. A perspectiva dos profissionais sobre o processo de alta de pacientes do Caps-AD: critérios e dificuldades. Saúde Debate 2019; 43:819-35.

61. Sanches L, Vecchia M. Reabilitação psicossocial e inclusão social de pessoas com problemas decorrentes do uso de álcool e outras drogas: impasses e desafios. Interface (Botucatu) 2020; 24:e200239.

62. Rigoni R, Breeksema J, Woods S. Speed limits harm reduction for people who use stimulants. https://idpc.net/publications/2018/09/speedlimits-harm-reduction-for-people-who-usestimulants (acessado em 20/Nov/2018).

63. Ribeiro JP, Gomes GC, Mota MS, Ortiz E, Eslabão AD. Strategies of care for adolescent users of crack undergoing treatment. Invest Educ Enferm 2019; 37:e12.

64. Lago RR, Bógus CM, Peter E. An exploration of the relational autonomy of people with substance use disorders: constraints and limitations. Int J Ment Health Addict 2020; 18:277-92.

65. Vasconcelos MP, Paiva FS, Vecchia MD. O cuidado aos usuários de drogas: entre normatização e negação da autonomia. Gerais (Univ. Fed. Juiz Fora) 2018; 11:363-81.

66. Subrinho Queiroz L, Sena E, Santos V, Carvalho P. Cuidado ao consumidor de drogas: percepção de enfermeiros da Estratégia de Saúde da Família. Saúde Soc 2018; 27:834-44.

67. Galhardi C, Matsukura T. O cotidiano de adolescentes em um Centro de Atenção Psicossocial de Álcool e outras Drogas: realidades e desafios. Cad Saúde Pública 2018; 34:e00150816.
68. Santos JM, Baptista JA, Nasi C, Camatta MW. Responsabilização e participação: como superar o caráter tutelar no centro de atenção psicossocial álcool drogas? Rev Gaúch Enferm 2018; 39:e20180078.

69. Paula ML, Jorge MB, Lima L, Bezerra I. Experiências de adolescentes em uso de crack e seus familiares com a atenção psicossocial e institucionalização. Ciênc Saúde Colet 2017; 22:2735-44.

70. Silveira M, Rosa D, Silva M, Farias FL, Moniz AS, Ventura J. Autonomia e reinserção social: percepção de familiares e profissionais que trabalham com redução de danos. Ciênc Cuid Saúde 2017; 16:34299.

71. Lago RR, Peter E, Bógus CM. Harm reduction and tensions in trust and distrust in a mental health service: a qualitative approach. Subst Abuse Treat Prev Policy 2017; 12:12.

72. Nasi C, Olivieira G, Lacchini AJ, Camatta M, Everling EM, Schneider JF. O trabalho da equipe orientado pelas motivações dos usuários no capsad: estudo fenomenológico. Rev Pesqui (Univ. Fed. Estado Rio J.) 2015; 7:3239-48.

73. Zanatta AB, Garghetti FC, Lucca SR. O centro de atenção psicossocial álcool e drogas sob a percepção do usuário. Rev Baiana Saúde Pública $2012 ; 36: 225-37$.

74. Moura FG, Santos JE. O cuidado aos usuários de um centro de atenção psicossocial álcool e drogas: uma visão do sujeito coletivo. SMAD Rev Eletrônica Saúde Mental Álcool Drog 2011; 7:126-32

75. Giffoni FA, Santos M. Terapia comunitária como recurso de abordagem do problema do abuso do álcool, na atenção primária. Rev Latinoam Enferm 2011; 19:821-30.

76. Oliveira E, Oliveira MAF, Claro HG, Paglione HB. Práticas assistenciais no Centro de Atenção Psicossocial de Álcool, Tabaco e outras Drogas. Rev Ter Ocup 2010; 21:247-54.

77. Pinho PH, Oliveira M, Vargas D, Marilia A, Machado A, Silva A, et al. Reabilitação psicossocial dos usuários de álcool e outras drogas: a concepção de profissionais de saúde. Rev Esc Enferm USP 2009; 43:1261-6.

78. Moraes M. Modelo de atenção integral à saúde para tratamento de problemas decorrentes do uso de álcool e outras drogas: percepções de usuários, acompanhantes e profissionais. Ciênc Saúde Colet 2008; 13:121-33.

79. Souza J, Kantorski LP, Mielke FB. Vínculos e redes sociais de indivíduos dependentes de substâncias psicoativas sob tratamento em CAPS AD. SMAD Rev Eletrônica Saúde Mental Álcool Drog 2006; 2:1-7. 


\section{Abstract}

The theoretical and practical frameworks that comprise the psychosocial paradigm in the field of drugs, featuring harm reduction and health promotion, focused attention on the suffering individual in relation to the social reality. Such frameworks value the uniqueness of users and healthcare workers for understanding the health-disease process and building effective health policies. The concept that underlies and unites these characteristics is autonomy. However, there are diverse definitions and practices pertaining to autonomy, with intrinsic plurality in the development of mental health and drug policy in Brazil. The article aims to describe the strategies for building autonomy for persons with abusive drug use. The method was an integrative review, searching the PsycInfo, PubMed, Virtual Health Library (VHL), and Web of Science databases for studies that analyzed the process of care for drug users. The review systematized actions that build autonomy and the barriers to care. Twenty-two studies were selected, of which 18 were studies in CAPS AD (Centers for Psychosocial Care for Alcohol and Drug Abuse) and 4 in primary care services. The review highlighted actions aimed at reclaiming individual social value, unique individual treatment plans, and harm reduction workshops. Barriers include the requirement of abstinence, lack of inter-sector collaboration, lack of social rehabilitation through work, and lack of participation in community and political spaces. The evidence points to a set of contradictory and diffuse practices, with some that build autonomy and others that impose control over users. Even so, the actions by CAPS AD and primary care are essential for reclaiming autonomy in the face of stigmatization and marginalization.

Personal Autonomy; Mental Health Services; Drug Abuse

\section{Resumen}

Los andamiajes teórico-prácticos que componen el paradigma psicosocial en el campo de las drogas, tales como la reducción de daños y la promoción de la salud, se centraron en el sujeto que padece el problema en relación con la realidad social. Ellos valoran la singularidad de consumidores y profesionales de la salud para la comprensión del proceso salud-enfermedad, así como la construcción de políticas de salud. El concepto que fundamenta $y$ agrega esas características es el de construcción de autonomía. No obstante, existen acepciones y acciones distintas, relacionadas con la autonomía, pluralidad intrínseca al desarrollo de la politica de salud mental y drogas en el país. El objetivo de este artículo es describir las estrategias para la construcción de autonomía para personas que consumen abusivamente drogas. El método utilizado fue la revisión integradora, donde se buscaron estudios, en las bases PsycInfo, PubMed, Biblioteca Virtual en Salud (BVS) y Web of Science, que analizaron el proceso de cuidado a consumidores de drogas. Se sistematizaron acciones que construyen autonomía, así como barreras para el cuidado. Se seleccionaron 22 estudios, siendo 18 investigaciones en Centro de Atención Psicosocial de Alcohol y otras Drogas (CAPS AD) y 4 en servicios de atención primaria. Sobresalieron las acciones realizadas en la dimensión de rescate de valor social como planes terapéuticos singulares y talleres de reducción de daños. Representan barreras la exigencia de abstinencia, la falta de acciones intersectoriales, falta de reinserción social por vínculos de trabajo y la no participación en instancias comunitarias y políticas. Se evidencia un conjunto de prácticas contradictorias y difusas, existiendo las que construyen autonomía y las que imponen el control sobre el usuario. No obstante, las acciones de los CAPS AD y atención primaria demuestran ser fundamentales para el rescate de la autonomía frente a la estigmatización y marginalización.

Autonomía Personal; Servicios de Salud Mental; Abuso de Drogas

Recebido em 06/Jan/2021

Versão final reapresentada em 14/Mar/2021

Aprovado em 01/Abr/2021 